\title{
Assessment of Posaconazole Salvage Therapy in Chronic Pulmonary Aspergillosis by Using Predefined Response Criteria
}

\author{
Goncer IR ${ }^{1}$, Harris $C^{1}$, Kosmidis $C^{1,2}$, Muldoon EG ${ }^{1,2}$, Newton $P J^{1}$ and Denning $\mathrm{DW}^{1,2^{*}}$ \\ ${ }^{1}$ The National Aspergillosis Centre, Wythenshawe Hospital, Manchester University NHS Foundation Trust, Manchester, United Kingdom \\ ${ }^{2}$ Manchester Academic Health Science Centre, The University of Manchester, Manchester, United Kingdom
}

"Corresponding author: David Denning, Professor, FRCP FRCPath FMedSci, The National Aspergillosis Centre, Wythenshawe Hospital, Manchester University NHS Foundation Trust, Southmoor Road, M23 9LT, Manchester, United Kingdom, Tel: +447754889658; E-mail: david.denning@manchester.ac.uk

Received date: January 22, 2018; Accepted date: January 24, 2018; Published date: January 27, 2018

Copyright: () 2018 Goncer IR, et al. This is an open-access article distributed under the terms of the Creative Commons Attribution License, which permits unrestricted use, distribution, and reproduction in any medium, provided the original author and source are credited.

\begin{abstract}
Objective: Chronic pulmonary aspergillosis (CPA) is a progressive infection that destroys lung tissue in immune competent patients. First-line therapies for CPA (itraconazole and/or voriconazole) are often curtailed due to toxicity or the development of drug resistance. Posaconazole is a potential alternative for these patients, but it is a high-cost medication.
\end{abstract}

Methods: Use of posaconazole was funded by the NHS Highly Specialised National Commissioners on an individual basis for patients who failed or did not tolerate first line therapy; those who met predefined criteria for improvement at 4 and 6 months (weight gain and/or improvement in St George's Respiratory Questionnaire) continued posaconazole long-term. We recorded response, failure, discontinuation rates and adverse events.

Results: Seventy-eight patients received posaconazole as salvage therapy. Thirty-four (44\%) achieved targets for continuation of therapy. Fourteen (18\%) failed therapy; $5(36 \%)$ patients did not achieve clinical targets at 4 or 6 months of assessment and $9(64 \%)$ developed clinical and/or radiological failure. Twenty-eight (36\%) discontinued their trial early; 8 (29\%) died and 20 (71\%) had significant side effects. One patient was non-compliant and another was lost to follow-up.

Conclusions: Establishing criteria for therapeutic success offered a clear, safe and sustainable method of identifying patients who benefit from additional therapy and minimised continuation of ineffective therapy in those who did not.

Keywords: Aspergillus fumigatus, Chronic pulmonary aspergillosis; Posaconazole

\section{Introduction}

Chronic pulmonary aspergillosis (CPA) is a slowly progressive infection mainly caused by Aspergillus fumigatus, characterized by inflammatory destruction of lung tissue with cavitation, pleural thickening and/or fibrosis, and associated with significant respiratory and constitutional symptoms [1-3]. CPA usually affects patients with underlying structural airway disease with cavities or bullae, such as tuberculosis (TB), non-tuberculous mycobacterial infection, chronic obstructive pulmonary disease (COPD), allergic bronchopulmonary aspergillosis (ABPA), pneumothorax and sarcoidosis. This entity is associated with significant morbidity and mortality [4-7]. In a recent large retrospective analysis of $387 \mathrm{CPA}$ patients, survival at 1,5 and 10 years from first visit was $86 \%, 62 \%$ and $47 \%$ respectively [8]. Worse outcomes were associated with NTM co-infection, COPD, pleural involvement, bilateral cavitary disease or aspergillomas, low body mass and low albumin.

Long-term treatment of CPA has been shown to improve symptoms and patients' functional status, prevent the progressive destruction of lung tissue and the development of pulmonary fibrosis, and reduce death rates and morbidity $[5,9]$. However, treatment is often long-term or lifelong and may be limited by intolerable side effects or the emergence of resistance [10]. Tri-azole antifungal agents, such as itraconazole and voriconazole, are the standard therapy recommended for CPA [9,11-16]. Posaconazole is a broad-spectrum tri-azole agent with potent activity against Aspergillus species. This agent has been shown to be a good alternative for patients with CPA [17] but, as other azole therapies, its use can be limited due to side effects, interactions and high cost. Additionally, all current data on the use of posaconazole in CPA are retrospective.

Assessing response to therapy in CPA is problematic, as patients may suffer from concomitant bacterial or mycobacterial infection, or from deterioration of underlying disease such as COPD or sarcoidosis. Most series on azole therapy for CPA show response rates between $44-80 \%$ [9,11-14,17], although criteria for response are not well characterised. Most of the studies include subjective and objective endpoints such as clinical, radiological, serological and microbiological criteria. Radiological improvement, the most objective criterion, is not always seen, in our experience, even if clinical improvement is evident. Use of Quality-of-Life (QoL) questionnaires such as the St George's Respiratory Questionnaire (SGRQ) has been validated in CPA and shown to correlate with clinical improvement [18]. Therefore, use of this questionnaire could be a way of determining which patients might benefit from long-term treatment with posaconazole, thereby limiting 
cost and toxicity by stopping a high-cost drug in patients who are unlikely to benefit.

The aim of this study is to assess whether pre-set targets of improvement in SGRQ and weight gain can be used as a criterion of response to posaconazole therapy in $\mathrm{CPA}$, in order to determine which patients respond to therapy, rather than denying treatment to all on the basis of cost and limited efficacy data.

\section{Materials and Methods}

\section{Study design}

A prospective service evaluation was undertaken to assess the response to posaconazole of adult patients with CPA at the National Aspergillosis Centre (NAC), Manchester University NHS Foundation Trust, Manchester, United Kingdom. The conditions for initiation of therapy and evaluation of response were set by the National Commissioning Group with responsibility for highly specialised services and implemented by the clinical team at the NAC. Broadly speaking the National Health Service is willing to provide high-cost therapies for patients that have exceptional benefit, but not for those with marginal or no benefit; criteria that are applied across multiple disciplines.

\section{Study subjects}

From February 2014 to October 2015, 78 adult patients with CPA who were resistant to, failed, or were intolerant to standard first-line antifungal treatment, or those who had contraindications to such first line therapy were offered posaconazole as a salvage therapy. There was no placebo or control arm, with response evaluated with each individual patient's weight and SGRQ scores at 4 and 6 months.

\section{Definitions}

The diagnosis of CPA was based on clinical, radiological and laboratory findings:

1. Chronic (duration $>3$ months) systemic or pulmonary symptoms (e.g. cough, haemoptysis, breathlessness, weight loss, fatigue and/or pyrexia),

2. Radiological evidence of a progressive (over months or years) pulmonary formation and expansion of single or multiple cavitations and associated pleural thickening,

3. Positive serum immunoglobulin $G(\operatorname{IgG})$ antibodies titre to Aspergillus fumigatus and/or positive sputum or bronchoscopy sample for Aspergillus spp. on culture, detectable galactomannan and/or Aspergillus DNA by polymerase chain reaction (PCR).

Other entities that could imitate CPA were excluded (e.g. mycobacterial infection, pulmonary malignancy) as were overt immunocompromising conditions [19,20].

Patients who received posaconazole had previously received antifungal therapy (itraconazole and/or voriconazole) and had refractory disease or intolerance. Patients were considered as "refractory" to first-line therapy if their clinical condition and/or laboratory test results had not improved after at least 6 months of therapy, or an azole resistant (but posaconazole-susceptible) Aspergillus spp. strain was isolated. Patients were considered "intolerant" to previous antifungal treatment if they developed adverse events necessitating drug discontinuation.

The SGRQ was used for quality of life assessment. It is a diseasespecific instrument designed to measure impact on overall health, daily life and perceived well-being in patients with pulmonary disease. The scale is scored from 0 to 100 , where the higher score indicates worse health status. The questionnaire has been previously validated in CPA patients $[18,21]$.

Assessment of improvement at 4 and 6 months was done according to the following criteria:

a. Clinical improvement was defined as being present if patients had $2 \mathrm{Kg}$ of weight gain and/or reduction of 8 points on the SGQR at 4 months and $3 \mathrm{Kg}$ of weight gain and/or reduction of 12 points on the SGQR at 6 months. These criteria are based on prior work by Jones et al. [22] and our own observations [18,23].

b. Clinical deterioration was defined as death or discontinuation of posaconazole because of an adverse event. Treatment-related adverse events were defined as any clinical incident attributed to posaconazole by doctors.

c. Clinical failure was considered if the patient did not meet targets at 4 or 6 months. Patients who fulfilled targets for improvement at the end of the 6-month initial period of therapy were offered long-term therapy with posaconazole for CPA.

\section{Study methods}

The purpose of the individual trial of therapy was explained to each patient and their verbal agreement sought both to take posaconazole and to accept that if they did not respond adequately (assuming no significant toxicity) then therapy would be discontinued. Clinical data, weight, laboratory test results and SGRQ prior to posaconazole antifungal therapy (baseline) were documented. In some cases, in whom good clinical responses had occurred with voriconazole, but long-term adverse events precluded further voriconazole use, the baseline SGRQ and weight prior to voriconazole were used to avoid requiring the patient to have a major deterioration before starting posaconazole.

Clinical response and the occurrence of adverse events were routinely evaluated at every clinic visit. Patients were evaluated at one month after starting posaconazole; liver function, serum posaconazole levels and patient-reported adverse events were checked at this visit. After 4 and 6 months on antifungal therapy, weight and SGRQ scores were measured.

\section{Laboratory methods}

Quantification of specific IgG to Aspergillus fumigatus in all serum samples was performed using the ImmunoCAP method (Phadia, Uppsala, Sweden). Aspergillus fumigatus specific IgE levels were assayed using a fluorescent enzyme immunoassay (Phadia), with a cutoff of $<0.4 \mathrm{IU} / \mathrm{L}$.

Therapeutic drug monitoring (TDM) was performed throughout the study measuring posaconazole levels at 1,4 and 6 months. Posaconazole plasma concentrations were determined using a longestablished bioassay; serum posaconazole concentration $>1 \mathrm{mg} / \mathrm{L}$ was considered satisfactory as therapeutic level $[24,25]$. 
Citation: Goncer IR, Harris C, Kosmidis C, Muldoon EG, Newton PJ, et al. (2018) Assessment of Posaconazole Salvage Therapy in Chronic Pulmonary Aspergillosis by Using Predefined Response Criteria. J Antimicrob Agents 4: 158. doi:10.4172/2472-1212.1000158

Page 3 of 6

Isolates of Aspergillus were identified to species complex level using standard microbiological techniques. Minimum inhibitory concentrations (MICs) to triazoles were determined by a modified European Committee on Antimicrobial Susceptibility Testing (EUCAST) method [26]. The modification was a lower final inoculum concentration $\left(0.5 \times 10^{5} \mathrm{CFU} / \mathrm{mL}\right.$, rather than $\left.1-2.5 \times 10^{5} \mathrm{CFU} / \mathrm{mL}\right)$. Isolates were tested against itraconazole, voriconazole, posaconazole and amphotericin B. Clinical and epidemiologic breakpoints used in this study were itraconazole and voriconazole $>2 \mathrm{mg} / \mathrm{L}$, posaconazole $>0.25 \mathrm{mg} / \mathrm{L}$ and amphotericin $>0.5 \mathrm{mg} / \mathrm{L}$ [27-29].

\section{Results}

\section{Patients' characteristics}

A total of 78 patients (56 men and 22 women) were offered posaconazole therapy; mean age of $48.5 \pm 12$ years, mean weight $48.9 \pm$ $18.5 \mathrm{Kg}$, and mean SGRQ score of $81.8 \pm 22.2$ points at baseline. All patients had previously received primary therapy with itraconazole and/or voriconazole (Table 1). Fifty-six out of 78 (72\%) patients were intolerant to previous therapy; 22 (39\%) due to severe photosensitivity, $8(14 \%)$ had developed peripheral neuropathy, 8 (14\%) had moderate or severe hepatitis, 7 (13\%) patients had persistent visual symptoms and 11 had other side effects such as hypertension, hair loss, ankle swelling, gastrointestinal intolerance or arrhythmias. Twenty-two out of $78(28 \%)$ patients were refractory to previous therapy; $7(32 \%)$ patients were infected with Aspergillus spp. resistant to itraconazole and/or voriconazole (Table 2 ) and $15(68 \%)$ had failed therapy.

\begin{tabular}{|c|c|c|}
\hline \multirow[b]{2}{*}{ Variables } & \multicolumn{2}{|l|}{ Patients $(n=78)$} \\
\hline & Mean (Range) & $\begin{array}{l}\mathrm{N} \\
(\%)\end{array}$ \\
\hline \multicolumn{3}{|l|}{ Demographic characteristic } \\
\hline Age, years, mean (range) & $48.5(38-80)$ & -- \\
\hline Male sex, patients & 56 & -- \\
\hline Weight, $\mathrm{Kg}$, mean (range) & $48.9(34-100)$ & -- \\
\hline \multicolumn{3}{|l|}{ Clinical and laboratory findings } \\
\hline $\begin{array}{l}\text { St George Respiratory Questionnaire, } \\
\text { median (range) }\end{array}$ & $81.8(8-100)$ & -- \\
\hline \multicolumn{3}{|l|}{ Diagnostic test results } \\
\hline $\begin{array}{l}\text { Aspergillus IgG antibody titer mean } \\
\text { (range) }\end{array}$ & $107.5(10-2000)$ & $62(79.5)$ \\
\hline $\begin{array}{l}\text { Aspergillus IgE antibody titer mean } \\
\text { (range) }\end{array}$ & $1.45(<0.4-72)$ & $42(53.8)$ \\
\hline C-reactive protein mean (range) & $24(1-148)$ & $58(74.4)$ \\
\hline Plasma viscosity mean (range) & $1.95(1.4-2.59)$ & $76(97.4)$ \\
\hline \multicolumn{3}{|c|}{ Azole therapy immediately preceding posaconazole } \\
\hline Itraconazole (\%) & $3(3.8)$ & -- \\
\hline Voriconazole (\%) & $75(96.2)$ & -- \\
\hline
\end{tabular}

Table 1: Patients' clinical characteristics, laboratory results and previous azole therapies.

\begin{tabular}{|c|c|c|c|c|}
\hline $\begin{array}{l}\text { Aspergillus } \\
\text { fumigatus } \\
\text { resistant } \\
\text { strain }\end{array}$ & MIC50 & $\begin{array}{l}\text { Previous } \\
\text { azole } \\
\text { therapy }\end{array}$ & $\begin{array}{l}\text { Serum } \\
\text { levels }\end{array}$ & $\begin{array}{l}\text { Response to } \\
\text { posaconazole } \\
\text { therapy }\end{array}$ \\
\hline \multirow{3}{*}{1} & Itraconazole >8 & \multirow{3}{*}{ Voriconazole } & \multirow{3}{*}{$\begin{array}{l}\text { Low } \\
\mathrm{mg} / \mathrm{L})\end{array}$} & \multirow{3}{*}{$\begin{array}{l}\text { Achieved } \\
\text { targets }\end{array}$} \\
\hline & Voriconazole >8 & & & \\
\hline & Posaconazole 1 & & & \\
\hline \multirow{3}{*}{2} & Itraconazole 1 & \multirow{3}{*}{ Voriconazole } & \multirow{3}{*}{$\begin{array}{l}\text { Satisfactory } \\
(1.3-5.7 \\
\mathrm{mg} / \mathrm{L})\end{array}$} & \multirow{3}{*}{$\begin{array}{l}\text { Achieved } \\
\text { targets }\end{array}$} \\
\hline & Voriconazole >8 & & & \\
\hline & $\begin{array}{l}\text { Posaconazole } \\
0.125\end{array}$ & & & \\
\hline \multirow{3}{*}{3} & Itraconazole>8 & \multirow{3}{*}{ Itraconazole } & \multirow{3}{*}{$\begin{array}{l}\text { Satisfactory } \\
(5-17 \mathrm{mg} / \mathrm{L})\end{array}$} & \multirow{3}{*}{ Clinical failure } \\
\hline & Voriconazole $>8$ & & & \\
\hline & $\begin{array}{l}\text { Posaconazole } \\
0.25\end{array}$ & & & \\
\hline \multirow{3}{*}{4} & Itraconazole>8 & \multirow{3}{*}{ Itraconazole } & \multirow{3}{*}{$\begin{array}{l}\text { Satisfactory } \\
(5-17 \mathrm{mg} / \mathrm{L})\end{array}$} & \multirow{3}{*}{$\begin{array}{l}\text { Achieved } \\
\text { targets }\end{array}$} \\
\hline & Voriconazole $>4$ & & & \\
\hline & Posaconazole 1 & & & \\
\hline \multirow{3}{*}{5} & Itraconazole >8 & \multirow{3}{*}{ Itraconazole } & \multirow{3}{*}{$\begin{array}{l}\text { Satisfactory } \\
(5-17 \mathrm{mg} / \mathrm{L})\end{array}$} & \multirow{3}{*}{ Clinical failure } \\
\hline & Voriconazole 2 & & & \\
\hline & $\begin{array}{l}\text { Posaconazole } \\
0.5\end{array}$ & & & \\
\hline \multirow{3}{*}{6} & Itraconazole >8 & \multirow{3}{*}{ Itraconazole } & \multirow{3}{*}{$\begin{array}{l}\text { Satisfactory } \\
(5-17 \mathrm{mg} / \mathrm{L})\end{array}$} & \multirow{3}{*}{$\begin{array}{l}\text { Achieved } \\
\text { targets }\end{array}$} \\
\hline & Voriconazole $>8$ & & & \\
\hline & Posaconazole 1 & & & \\
\hline \multirow{3}{*}{7} & Itraconazole 2 & \multirow{3}{*}{ Voriconazole } & \multirow{3}{*}{$\begin{array}{l}\text { Satisfactory } \\
(1.3-5.7 \\
\mathrm{mg} / \mathrm{L})\end{array}$} & \multirow{3}{*}{ Intolerance } \\
\hline & Voriconazole 8 & & & \\
\hline & $\begin{array}{l}\text { Posaconazole } \\
0.25\end{array}$ & & & \\
\hline
\end{tabular}

Table 2: In vitro susceptibility testing of azole-resistant Aspergillus strains and previous therapy drug-levels collected at baseline.

\section{Laboratory and microbiology data at baseline}

Aspergillus IgG titres were above the normal range $(0.0-40.0 \mathrm{mg} / \mathrm{L})$ in $62 / 78$ (79\%) patients. Forty-two patients out of 78 (54\%) had raised Aspergillus IgE titres half of those with Aspergillus IgG titres in the normal range had high Aspergillus IgE levels. Twelve of the 'seronegative' CPA patients had previously had an abnormal Aspergillus IgG; in those who didn't diagnosis was supported by combinations of biopsies showing fungal hyphae, aspergilloma(s) present on chest computed tomography (CT) scan with positive Aspergillus cultures, Aspergillus PCR, galactomannan and microscopy showing hyphae (or a combination) from respiratory tract samples. 
Page 4 of 6

\section{Response to therapy}

Thirty-four out of 78 (44\%) patients achieved clinical targets for continuation of therapy. Figure 1 shows clinical targets achieved by these patients.

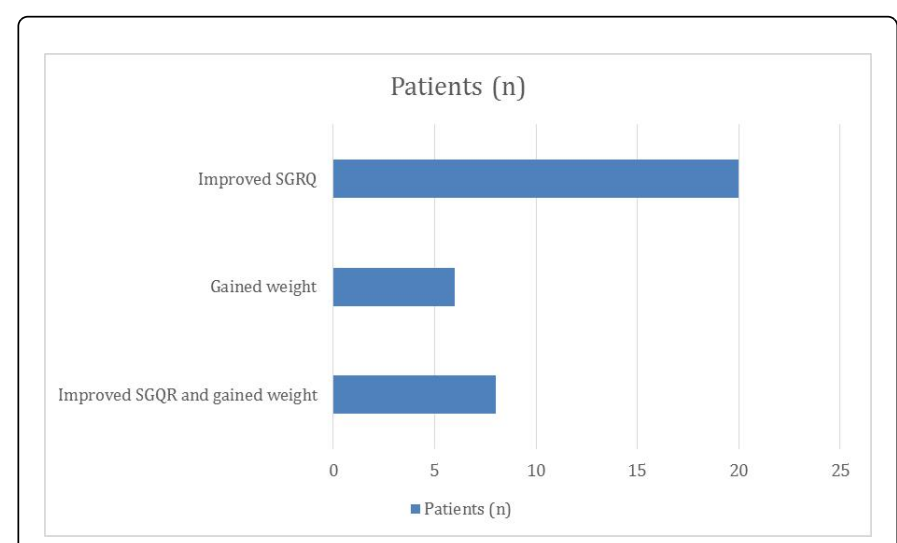

Figure 1: Targets achieved at the end of 4 and/or 6 months by those 34 patients who fulfilled pre-specified criteria.

Fourteen out of 78 (18\%) patients failed to achieve targets; 2 (14\%) did not achieve clinical targets at 4 months, $3(21 \%)$ achieved targets at 4 months but not at 6 months, and $9(64 \%)$ developed clinical and/or radiological failure despite treatment. In forty-three patients side effects occurred but this led to stopping treatment only in 20/78 (26\%) patients; one patient developed intense fatigue despite low posaconazole levels, twelve $(60 \%)$ had therapeutic levels of posaconazole when side effects appeared and seven (35\%) patients stopped treatment before levels were checked. Eight out of 78 (10\%) patients died during the trial. All of them had severe pulmonary disease with very limited lung function that clearly contributed to their demise. Patients' outcomes are shown in Figure 2.

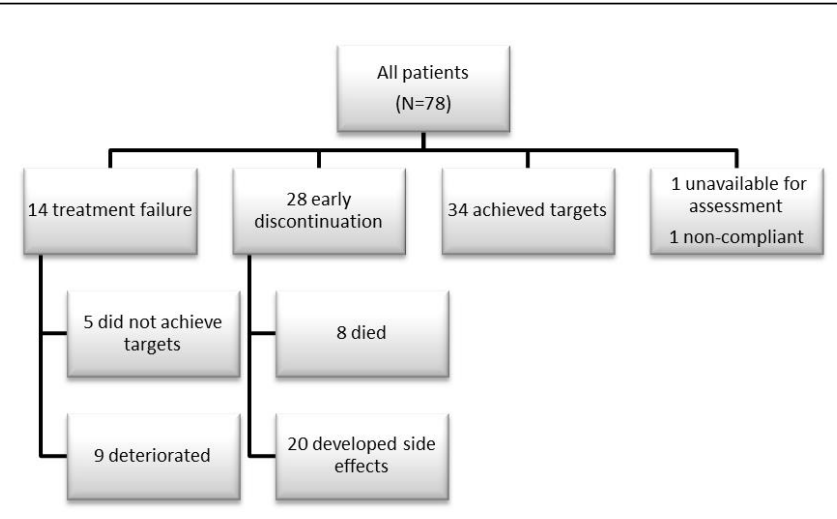

Figure 2: Outcome of patients receiving Posaconazole as salvage therapy.

Seventy-two out of 78 (92\%) patients received posaconazole tablets and $6(8 \%)$ were treated with liquid formulation. Eighteen out of 78 (23\%) patients needed dose-adjustment after TDM results. Three patients had persistently sub-therapeutic posaconazole levels with liquid formulation that was resolved after switching to tablets. Another three patients were changed from liquid to a more convenient daily tablet formulation to simplify therapy without having any impact on the levels, tolerance and clinical response. Only one patient was changed from tablet to liquid formulation due to side effects of lethargy and fatigue that reduced after the alteration in formulation.

Seventy-five patients were receiving voriconazole therapy before starting posaconazole, $21 / 75$ (28\%) were refractory and 54/75 (72\%) were intolerant to it. Seventeen among those who were refractory to voriconazole $(17 / 21,80 \%)$ and 46 of those who were intolerant to it (46/54, 85\%), did respond to the trial. Two patients who had experienced a significant response to voriconazole but were unable to continue it due to severe side effects met the assessed criteria based on the data before starting voriconazole and were continued to posaconazole with significant clinical response in the long term.

\section{Side effects}

Forty-three out of 78 (55\%) patients developed side effects but only $20(51 \%)$ stopped the treatment. Sixteen of $20(80 \%)$ patients stopped posaconazole within the first 4 months and $4(20 \%)$ before reaching the 6 months' follow-up. Reported side effects are shown in Figure 3.

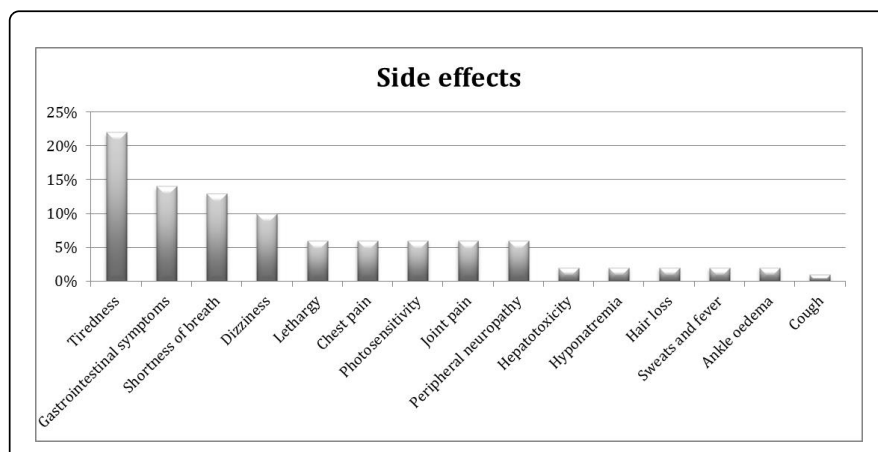

Figure 3: Percentage of adverse events related to posaconazole.

One patient with hyponatraemia required hospital admission. One patient reported suicidal ideation. One patient developed symptomatic sinus bradycardia that improved after reducing the dose of posaconazole. Five patients out of $78(6 \%)$ had residual peripheral neuropathic symptoms due to previous azole therapy before starting posaconazole treatment; $3(60 \%)$ experienced deterioration in their peripheral neuropathy on posaconazole that led to discontinuation. Photosensitivity attributable to previous voriconazole treatment was a reason for posaconazole therapy in $22 / 78$ (28.2\%) patients; only two of these patients experienced this side effect with posaconazole, one of whom discontinued therapy.

The most common adverse event reported was fatigue that occurred in $17 / 78(22 \%)$ patients and led to discontinuation of therapy in all affected patients. Five of them had high serum drug levels at the time of discontinuation of therapy but most of them stopped therapy and drug level was not measured. Among those who stopped treatment because of side effects, 19/20 (95\%) had previously experienced some intolerance with another azole antifungal. However, of those 23 who did not report significant side effects with posaconazole, $66.7 \%(n=20)$ had previously had intolerance to another azole agent.

\section{Discussion}

CPA is a chronic, highly symptomatic and potentially fatal disease and antifungal treatment probably improves life expectancy in these 
Page 5 of 6

patients [8]. Despite benefits of antifungals, long-term usage still remains a challenge, with patient variations in exposure and metabolism, appreciable toxicity, notable drug interactions, emergence of azole-strain resistance and high drug costs $[5,10,15]$. Forty-four percent of patients in our trial benefited from posaconazole therapy as a salvage therapy for CPA based on achievement of predefined targets in the SGRQ and weight as a surrogate marker of disease response. Our response rate is slightly lower than previous similar studies of CPA with first-line therapies $[9,11,13,14,17]$, although it is expected that salvage therapy would be less effective than first-line therapy. Use of the SGRQ to assess treatment response could be used as a surrogate marker in CPA or other chronic infections such as pulmonary nontuberculous mycobacterial disease.

This type of trial is applicable when the use of more expensive agents is restricted to those patients who have tried and failed less expensive agents in the same therapeutic class. In our study, almost half of the patients showed evidence of response and therefore derived benefit from high-cost therapy. The results of the trials indicate that many of these patients have no major benefit from the more expensive agent, and the cost savings from identifying responders and nonresponders can, in some cases, justify the cost of undertaking this therapeutic trial.

The estimated survival rate of CPA varies on different studies ranging between $49-62 \%$ at 5 years and $26-74 \%$ at 10 years $[6,8,30]$. Azoles are the only oral treatment options for these patients. Itraconazole and voriconazole are first-line treatment choices $[15,16]$ with efficacy rates ranging between $60-77 \%$ without clear differences between them [9,11-14]. However, their use often entails drug-related toxicities and emergence of Aspergillus spp. resistance [10]. A previous retrospective assessment from our center to assess the safety and efficacy of posaconazole treatment in 79 patients with CPA showed an improvement in $61 \%$ of patients at 6 months and in $46 \%$ at 12 months, which were comparable with success rates observed for itraconazole and voriconazole administration. In this study, $44 \%$ of patients reported improvements in quality of life, such as improved appetite, enhanced energy levels, improved pulmonary symptoms and managing day-to-day tasks better. These parameters are the essential clinical aims for CPA patients on treatment [18]. In a recent study by Newton et al. [31] to assess the impact of liposomal Amphotericin B on CPA patients, St George's quality of life questionnaire was used pre and post 36 courses of treatment; improvement was observed in $91.7 \%$ $(33 / 36)$ of treatment courses.

Azole therapy is frequently limited by adverse events [17,32]. In our trial more than $50 \%$ of patients developed side effects, which curtailed posaconazole therapy in about half and most of them had had previous azole therapy intolerance. This contrasts with the data previously published from our center on the use of posaconazole suspension in CPA [17]; only 12 of 79 (15\%) of patients reported an adverse reaction on posaconazole suspension, and 9 had to stop the drug. Most of our patients were treated with posaconazole tablets which achieve higher levels than the liquid formulation. For posaconazole, it is not known what drug level cut-off is associated with an increased level of toxicity (as is known e.g. for voriconazole). Therefore, some patients may need a lower posaconazole dose than the $300 \mathrm{mg}$ daily recommended dose for improved tolerability. Further studies are needed to define the ideal levels to prevent toxicity. The most common adverse events previously reported were gastrointestinal complaints and headaches $[17,33,34]$; interestingly, in our study fatigue was the most commonly reported side effect.
Unfortunately, only seven of our patients had a positive culture for Aspergillus spp. prior to their assignment on the trial. Cross-resistance among azoles is a common problem in this patient group and must be carefully considered before administration [35]. Seven patients were found to have Aspergillus fumigatus isolates resistant to itraconazole and/or voriconazole before the trials started. MIC breakpoints were agreed by EUCAST for posaconazole and Aspergillus fumigatus, based on pharmacodynamics modelling for invasive aspergillosis. We elected to treat 3 patients with 'posaconazole resistant' strains, who surprisingly achieved targets at 4 and 6 months despite these previous isolates.

To conclude, establishing criteria for therapeutic success offered a clear, equitable and sustainable method of identifying patients who benefit from additional therapy, and minimised continuation of ineffective therapy in those who did not. Use of long-term posaconazole tablets should be monitored with therapeutic level monitoring, with dose reduction when possible in order to limit toxicity.

\section{Acknowledgements}

We would like to thank the Mycology Reference Centre Manchester (MRCM) for their assistance in susceptibility tests and posaconazole levels, also to the nurses from the National Aspergillosis Centre for their contribution to patient care, and to Alison Smith, Pauline Wright and Graham Atherton for their support in analysing the SGRQ questionnaires data.

\section{Funding}

These trials were supported by the National Commissioning Group (NAC) at the University Hospital of South Manchester.

\section{Transparency Declarations}

IRG, $\mathrm{CH}$ and PJN have no potential conflicts of interest. CK has received speaker fees from Astellas. EGM has travel costs from Gilead and Astellas, advisory board fees from Gilead and speaker fees from Gilead, Astellas and Pfizer. DWD and family hold Founder shares in F2G Ltd, a University of Manchester spin-out antifungal discovery company. He acts or has recently acted as a consultant to Scynexis, Cidara, Biosergen, Quintiles, Pulmatrix, Pulmocide, Zambon, Fujifilm and Roivant. In the last 3 years, he has been paid for talks on behalf of Astellas, Dynamiker, Gilead, Merck and Pfizer. He is a longstanding member of the Infectious Disease Society of America Aspergillosis Guidelines group, the European Society for Clinical Microbiology and Infectious Diseases Aspergillosis Guidelines group and the British Society for Medical Mycology Standards of Care committee.

\section{Author Contributions}

IR participated in the data collection and manuscript writing, drafting and reviewing. $\mathrm{CH}$ participated in data collection and manuscript reviewing. PN, CK and EM participated in clinical care of patients and manuscript reviewing. DWD participated in the service evaluation design, manuscript writing, editing and reviewing. All authors read and approved the submitted manuscript. 


\section{References}

1. Denning DW, Riniotis K, Dobrashian R, Sambatakou H (2003) Chronic cavitary and fibrosing pulmonary and pleural aspergillosis: Case series, proposed nomenclature change and review. Clin Infect Dis 37: S265-280.

2. Patterson KC, Strek ME (2014) Diagnosis and treatment of pulmonary aspergillosis syndromes. Chest 146: 1358-1368.

3. Desai SR, Hedayati V, Patel K, Hansell DM (2015) Chronic aspergillosis of the lungs: Unravelling the terminology and radiology. Eur Radiol 25: 3100-3107.

4. Denning DW, Pleuvry A, Cole DC (2011) Global burden of chronic pulmonary aspergillosis as a sequel to pulmonary tuberculosis. Bul World Health Organ 89: 864-872.

5. Brown GD, Denning DW, Gow NAR, Levitz SM, Netea MG, et al. (2012) Hidden killers: Human fungal infections. Sci Transl Med 4: 1-10.

6. Nakamoto K, Takayanagi N, Kanauchi T, Ishiguro T, Yanagisawa T, et al. (2013) Prognostic factors in 194 patients with chronic necrotizing pulmonary aspergillosis. Intern Med 52: 727-734.

7. Denning DW, Bromley MJ (2015) How to bolster the antifungal pipeline Science 347: 1414-1416.

8. Lowes D, Al-Shair K, Newton PJ, Morris J, Harris C, et al. (2015) Predictors of mortality in chronic pulmonary aspergillosis. Eur Respir 49: 1601062.

9. Agarwal R, Vishwanath G, Aggarwal AN, Garg M, Gupta D, et al. (2013) Itraconazole in chronic cavitary pulmonary aspergillosis: A randomised controlled trial and systematic review of literature. Mycoses 56: 559-570.

10. Denning DW, Park S, Lass-Florl C, Fraczek MG, Kirwan M, et al. (2011) High-frequency triazole resistance found in nonculturable aspergillus fumigatus from lungs of patients with chronic fungal disease. Clin Infect Dis 52: 1123-1129.

11. Sambatakou H, Dupont B, Lode H, Denning DW (2006) Voriconazole treatment for subacute invasive and chronic pulmonary aspergillosis. Am J Med 119:17-24.

12. Camuset J, Nunes H, Dombret MC, Bergeron A, Henno P, et al. (2007) Treatment of chronic pulmonary aspergillosis by voriconazole in nonimmunocompromised patients. Chest 131: 1435-1441.

13. Cadranel J, Philippe B, Hennequin C, Bergeron A, Bergot E, et al. (2012) Voriconazole for chronic pulmonary aspergillosis: A prospective multicenter trial. Eur J Clin Microbiol Infect Dis 31: 3231-3239.

14. Saito T, Fujiuchi S, Tao Y, Sasaki Y, Ogawa K, et al. (2012) Efficacy and safety of voriconazole in the treatment of chronic pulmonary aspergillosis: Experience in Japan. Infection 40: 661-667.

15. Denning DW, Cadranel J, Beigelman-Aubry C, Ader F, Chakrabarti A, et al. (2016) Chronic pulmonary aspergillosis: Rationale and clinical guidelines for diagnosis and management. Eur Respir J 47: 45-68.

16. Patterson TF, Thompson GR, Denning DW, Fishman JA, Hadley S, et al. (2016) Practice guidelines for the diagnosis and management of aspergillosis: 2016 update by the infectious diseases society of America. Clin Infect Dis 63: e1-60.

17. Felton TW, Baxter C, Moore CB, Roberts SA, Hope WW, et al. (2010) Efficacy and safety of posaconazole for chronic pulmonary aspergillosis. Clin Infect Dis 51: 1383-1391.

18. Al-Shair K, Atherton GTW, Kennedy D, Powell G, Denning DW, et al. (2013) Validity and reliability of the St. George's respiratory questionnaire in assessing health status in patients with chronic pulmonary Aspergillosis. Chest 144: 623-631.

19. Pauw BD, Walsha TJ, Donnellya JP, Stevens D, Edwards JE, et al. (2008) Revised definitions of invasive fungal disease from the european organization for research and treatment of cancer/invasive. Clin Infect Dis 46: 1813-1821.

20. Walsh TJ, Anaissie EJ, Denning DW, Herbrecht R, Kontoyiannis DP, et al. (2008) Treatment of Aspergillosis: Clinical practice guidelines of the infectious diseases Society of America. Clin Infect Dis 46: 327-360.

21. Al-Shair K, Atherton GT, Harris C, Ratcliffe L, Newton PJ, et al. (2013) Long-term antifungal treatment improves health status in patients with chronic pulmonary aspergillosis: A longitudinal analysis. Clin Infect Dis 57: 828-835.

22. Jones PW (2002) Interpreting thresholds for a clinically significant change in health status in asthma and COPD. Eur Respir J 19: 398-404.

23. Al-Shair K, Muldoon EG, Morris J, Atherton GT, Kosmidis C, et al. (2016) Characterisation of fatigue and its substantial impact on health status in a large cohort of patients with chronic pulmonary aspergillosis (CPA). Respir Med 114: 117-122.

24. Bueno EC, Forastiero A, Tudela JLR, Estrella MC, Lopez AG (2012) HPLC/UV or bioassay: Two valid methods for posaconazole quantification in human serum samples. Clin Microbiol Infect 18: 1229-1235.

25. Brüggemann RJM, Touw DJ, Aarnoutse RE, Verweij PE, Burger DM (2009) International interlaboratory proficiency testing program for measurement of azole antifungal plasma concentrations. Antimicrob Agents Chemother 53: 303-305.

26. Tafin UF, Clauss M, Hauser PM, Bille J, Meis JF, et al. (2012) Isothermal microcalorimetry: A novel method for real-time determination of antifungal susceptibility of Aspergillus species. Clin Microbiol Infect 18: E241-245.

27. Tudela JLR, Fuoli LA, Mellado E, Izquierdo AA, Monzon A, et al. (2008) Epidemiological cutoffs and cross-resistance to azole drugs in Aspergillus jumigatus. Antimicrob Agents Chemother 52: 2468-2472.

28. Verweij PE, Howard SJ, Melchers WJG, Denning DW (2009) Azoleresistance in Aspergillus: Proposed nomenclature and breakpoints. Drug Resist Updat 12: 141-147.

29. Arendrup MC, Estrella MC, Flörl CL, Hope W, Arendrup MC, et al. (2012) EUCAST technical note on Aspergillus and amphotericin B, itraconazole, and posaconazole. Clin Microbiol Infect 18: E248-250.

30. Nam HS, Jeon K, Um SW, Suh GY, Chung MP, et al. (2010) Clinical characteristics and treatment outcomes of chronic necrotizing pulmonary aspergillosis: a review of 43 cases. Int J Infect Dis 14: e479-482.

31. Newton PJ, Harris C, Morris J, Denning DW (2016) Impact of liposomal amphotericin B therapy on chronic pulmonary aspergillosis. J Infect 73 : 485-495.

32. Huang X, Wang F, Chen Y, Liu T, Wang J, et al. (2012) A multicenter, open-label study of posaconazole oral suspension in the treatment of invasive fungal infections in patients refractory to or intolerant of firstline therapy. Future Microbiol 7: 201-209.

33. Raad II, Graybill JR, Bustamante AB, Cornely OA, Flores VG, et al. (2006) Safety of long-term oral posaconazole use in the treatment of refractory invasive fungal infections. Clin Infect Dis 42: 1726-1734.

34. Torres HA, Hachem RY, Chemaly RF, Kontoyiannis DP, Raad II (2005) Posaconazole: A broad-spectrum triazole antifungal. Lancet Infect Dis 5: 775-785.

35. Howard SJ, Cerar D, Anderson MJ, Albarrag A, Fisher MC, et al. Frequency and evolution of azole resistance in Aspergillus fumigatus associated with treatment failure. Emerg Infect Dis 15: 1068-1076. 